International Journal of MCH and AIDS (2018), Volume 7, Issue I, 9-I6

\begin{tabular}{ll}
\hline & INTERNATIONAL JOURNAL \\
& of MCH and AIDS \\
& ISSN 216I-864X (Online) \\
IJMA & ISSN 2161-8674 (Print) \\
& DOI: I0.21 I06/ijma.2 I7 \\
\hline
\end{tabular}

ORIGINALARTICLE

\title{
Nutritional Assessment and Maternal Perception of Toddler Body Size using Toddler Silhouette Scale in Nigeria a Developing Country
}

\author{
Oluwafunmilayo Funke Adeniyi, MBBS, FMC (Paed) Nig, Msc; ${ }^{1 凶}$ Ekanem Ekure, FWACP;' \\ Foluke A. Olatona, MBBS, FMCPH, MPH, Msc;² Elizabeth O. Ajayi, MBBS;' Nwaoma Nworgu, MBBS' \\ 'Department of Paediatrics, College of Medicine, Lagos University Teaching Hospital, University of Lagos, Idi-Araba, Lagos, NIGERIA; ${ }^{2}$ Department of \\ Community Health, College of Medicine, University of Lagos, NIGERIA \\ $\square$ Corresponding author email: layo_funke@yahoo.co.uk
}

\section{ABSTRACT}

Background and Objectives: The toddler silhouettes scales have been validated in the caucascian population in developing countries but in the African population, the use of these scales is yet to be evaluated. The aim of this study was to determine the perception of mothers on the body size of toddlers using a validated scale in an African population.

Methods: This was a cross sectional study of 241 mothers and their toddlers. Study participants were recruited from the immunization and pediatric clinics. The mothers' perceptions of the body sizes of toddlers and their own child was determined with the use of a validated 7-scale toddler silhouette. Each mother also assessed their own child with the scale. Each child's anthropometry was documented.

Results: Majority of the mothers were able to correctly classify the underweight $(95.0 \%)$ and overweight toddler silhouettes (95.7\%). However, 30\% of the respondents misclassified Silhouette 6 (overweight silhouette) as normal and $48.2 \%$ of the respondents misclassified a normal silhouette as underweight. The overall maternal accuracy in assessing their toddler size was $4 \mathrm{I}$. $1 \%$. There was a significant relationship between maternal accuracy and the maternal educational status, tribe, and toddler size.

Conclusions and Global Health implications: Toddler silhouette scales is a quick way of assessing the body size of children and could be of significant use in the developing countries. There is a need for caregivers to accurately assess the body size of their children as this will significantly influence the food mothers will give their children and thus children's eventual growth and development.

Key words: Toddler Silhouette • Nutritional Assessment • Child Anthropometry • Developing Countries • Childhood Obesity • Nigeria

Copyright (C) 20I8 Adeniyi et al.This is an open-access article distributed under the terms of the Creative Commons Attribution License, which permits unrestricted use, distribution, and reproduction in any medium, provided the original work is properly cited.

\section{Introduction}

Globally, there has been an epidemic of childhood obesity and this has not excluded the developing countries like Nigeria.' Over the last two decades, the rates of overweight and obesity among preschool African children has doubled from 4 to $8.5 \%$ between 
1990 and 2010 and is expected to reach $12.7 \%$ by the year $2020 .^{2}$ Reports from Nigeria have documented prevalence rates which vary from $5 \%-11 \%{ }^{3,4}$ from different parts of the country in the last decade thus the country like other developing countries is now facing the double burden of malnutrition i.e. undernutrition and overweight/obesity.

With this upsurge in pediatric obesity and its attendant complications, there is increasing need for identification of children who are overweight and obese so that appropriate prevention strategies can be instituted. ${ }^{2}$ The use of pediatric silhouette tools has been employed in many developed countries to enable parents and caregivers recognise overweight and obesity in toddlers and older children. ${ }^{1,5-7}$ Recognition of child weight considerably influences parental choice in feeding patterns and such choices impact on the nutritional status of children remarkably. ${ }^{1,6-8}$ Different pediatric silhouette scales are available and have been validated for use in research and clinical settings.,5-7 The toddler silhouette scales in particular have been used by parents/caregivers and health professionals and comparative studies between these two groups in the recognition of normal sized children or otherwise have been found to be remarkably useful in the clinical settings.' However, in the African population and particularly in the Nigerian context the use of the silhouette scale has not really been employed for studies on childhood obesity or undernutrition. Thus, the aims of this study were to I) determine the nutritional status of toddlers, 2) examine the accuracy of maternal perceptions of the toddler body size with the use of the toddler silhouette scale; and 3) identify the factors associated with maternal accuracy in an African population.

\section{Methods}

This was a cross-sectional study carried out over a 6-month period (May-October 2013) at the Lagos University Teaching Hospital (LUTH), Lagos, Nigeria. Lagos is a cosmopolitan city in Nigeria, West Africa, with an estimated population of up to 20 million. The LUTH is a tertiary center which receives referrals from within Lagos and from different parts of the country. The study participants were recruited from the Community Health Outpatient and pediatric clinics of the hospital. These clinics serve a diverse population from the high, middle and low socioeconomic class of the Lagos metropolis and its environs. Two hundred and forty one (24I) motherchild pairs were recruited into the study using consecutive sampling technique. Ethical approval was obtained from the Health Research and Ethics committee of the Lagos University Teaching Hospital. Informed written consent was obtained from the parents of the children and confidentiality of all the information obtained from the study participants was ensured.

\section{I. Data collection}

Children who were aged I-3 years in apparent good state of health and their mothers were recruited into the study. Children aged I-3 years with chronic illness or acute illness at the time of the study and their mothers were excluded from the study. Data collection tools were questionnaire to obtain sociodemographic status, proforma for anthropometry and the validated Toddler silhouette scale. The scale was manufactured by health care professionals at the University of Maryland Baltimore.'

Information on socio-demographic data such as name, age, sex, class of the child and the education and occupation of the parents/care givers were obtained. Anthropometry, specifically weight, length/ height were measured. Weight was measured with a digital scale after checking for zero error at each measurement and read to the nearest $0.1 \mathrm{~kg}$. Subjects were weighed barefoot, standing still and without support, in light clothing. Belts and other accessories were removed and pockets emptied. Length was measured in the recumbent position with the use of a measuring mat/tape. Height in children who could stand was measured with a stadiometer to the nearest 0.5 centimeter with subject's barefeet, standing erect with heels together and looking straight ahead in Frankfort plane. The lower borders of the socket were in the same horizontal plane as the external auditory meatus with heels and back against the height meter. ${ }^{8}$ Weight and length/ height were used to determine body mass index (BMI). Weight status was determined based on 
the World Health Organization (WHO) weightfor-length percentiles which define underweight as less than the $15^{\text {th }}$ percentile, healthy weight is in the $15^{\text {th }}$ percentile or more and less than the $85^{\text {th }}$ percentile and overweight is the $85^{\text {th }}$ percentile or more. Body mass index [calculated as weight in kilograms divided by height in meters squared] [BMI] for age was also determined.' Thus, the toddlers were categorized into these groups underweight, normal and overweight.

\subsection{Determination of toddler body sizes}

The parents/caregivers perception of the body sizes/nutritional status of toddlers generally were determined with the use of a validated 7-image Toddler silhouette scale (standardized photographs) which represents toddlers between 12 and 36 months of age with neutral ethnicity, race and gender. The Toddler Silhouette Scale images range from the 0 to the $100^{\text {th }}$ weight-for-length percentile, in increments of $16(0,16,32,48,64,80$, and 96). This scale represents toddlers with nutritional status in 3 different categories namely, underweight, normal and over nutrition. The toddler silhouettes represented in these pictures had been validated by a group of experts which comprised of health care professionals with expertise in pediatrics(pediatricians, child psychologists and psychiatrists, nurses, nutritionists and dieticians) and (ii) parents of toddlers aged 12-36 months.' The health professionals were recruited from schools of medicine and public health of the University of Maryland, Baltimore and from WIC (the Special Supplemental Nutrition Program for Women, Infants, and Children) under the same University. Parents were recruited from primary care clinics, and WIC clinics' (See figure I).According to the silhouettes in the toddler scale the toddlers were also categorized with into underweight, normal and overweight which was also consistent with the WHO categories.

\subsection{Determination of maternal accuracy}

In order to determine the maternal perceptions and accuracy of their children's body sizes, the validated seven image Toddler silhouette scale was used (see figure I). Each mother was asked the question "which picture best represents your child" to determine the maternal accuracy.An allowance of one silhouette on either side of the child's measured weight for length was made for the answers and responses that were two or more images smaller/larger than her child's weight for length points difference) were considered inaccurate. Data were evaluated in three categories i.e. inaccurate/perceived child as smaller, accurate or inaccurate/perceived child as larger.

\subsection{Statistical Analysis}

Data was analysed using the Statistical Package for Social Sciences (SPSS) version 21 . Basic descriptive statistics (frequencies, proportions, means, and standard deviations [SD]) were calculated for all of the items of the questionnaire and the $95 \%$ confidence intervals $(\mathrm{Cl})$ for the proportions were estimated by standard statistical analytical methods. Univariate analysis for the factors associated with maternal accuracy in determination of the

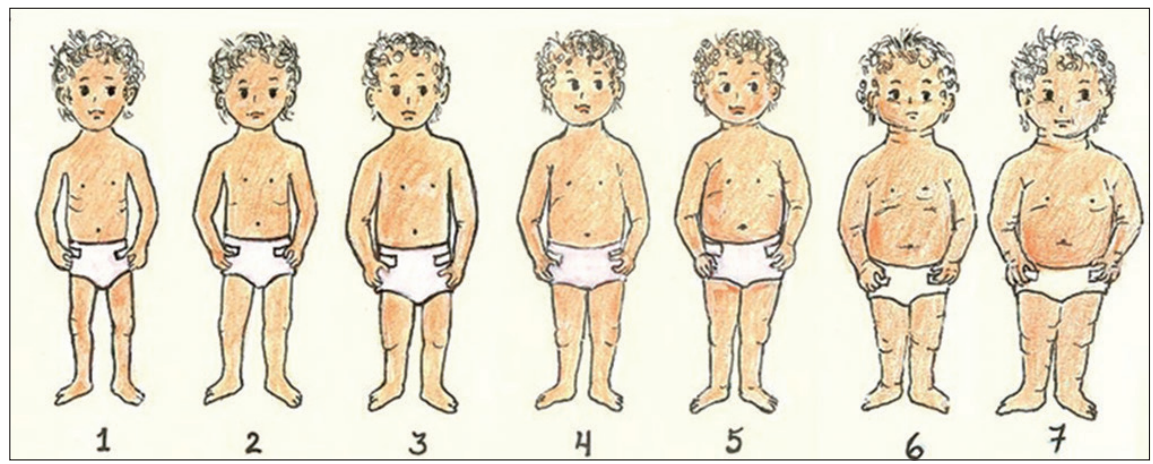

Figure I:Toddler Silhouette Scale: I- Underweight, 2-5 Normal, 6-7 Overweight

Adapted from: Hager ER McGill AE, Black MM. Development and validation of a toddler silhouette scale. Obesity. 20I0; I8(2):397-40 I 
toddler size was done with the chi square statistics. Logistic regression analysis was used to determine the factors that predicted the maternal accuracy and odds ratio and $95 \% \mathrm{Cl}$ for maternal accuracy were calculated. The level of significance was set at $\mathrm{p}<0.05$.

\section{RESULTS}

\section{I. Sociodemographic and nutritional status of the study participants}

A significant proportion (70.0\%) of the mothers were university graduates and were gainfully employed as senior civil servants or large scale entrepreneurs (49\%) while about a quarter attended secondary school and $18.3 \%$ were not employed. Most of the mothers were Christians $(86.7 \%)$ and half of them were from Igbo tribe. (50.2\%) (see Table I). More than half (56.6\%) of the children were males and the mean (SD) age was I.I $( \pm 0.99)$ years. Assessment of nutritional status of the children showed that $24.9 \%$ were underweight, $58.5 \%$ had healthy normal weights, while $16.6 \%$ were overweight (Tablel).

Majority of the mothers were able to correctly classify the underweight and overweight toddler silhouettes. Ninety-five percent of the mothers correctly classified silhouette one as underweight and $95.7 \%$ correctly classified silhouette seven as overweight. A significant proportion of the mothers were also able to identify the silhouettes three to five as normal-weight toddler silhouettes $(75.5 \%$, $78.1 \%$ and $77.61 \%$ respectively). However, $48.2 \%$ of the mothers failed to recognize silhouette two as normal weight and misclassified the silhouette as underweight, and $13 \%$ misclassified silhouette five as overweight while $30 \%$ of the respondents misclassified Silhouette six which is overweight as normal (Table 2).

\subsection{Maternal accuracy}

Table 3 show the actual nutritional status/toddler size in relation to the maternal accuracy.

Only 4I.I\% of the mothers who were willing to document their child nutritional status with the silhouette could accurately predict their child's nutritional status using the silhouette scale. $50.5 \%$
Table I: Socio-demographic characteristics of the toddlers and their mothers

\begin{tabular}{|c|c|}
\hline Toddler characteristics & Frequency (\%) \\
\hline Age $(($ mean $\pm s d)$ & $1.11 \pm 1.02$ \\
\hline Sex (male) & $196(56.6)$ \\
\hline Weight for length (Z score): Mean (range) & $0.41(-5.7-6.40)$ \\
\hline Exclusively breast fed & $67(28)$ \\
\hline Age of introduction of solids & $0.64 \pm 0.16$ \\
\hline \multicolumn{2}{|l|}{ Weight status } \\
\hline $\begin{array}{l}\text { Under weight }\left(<15^{\text {th }} \text { weight for length }\right. \\
\text { percentile) }\end{array}$ & $60(24.9 \%)$ \\
\hline $\begin{array}{l}\text { Healthy/normal }\left(15^{\text {th }}-85^{\text {th }} \text { weight for }\right. \\
\text { length percentile) }\end{array}$ & $|4|(58.5)$ \\
\hline $\begin{array}{l}\text { Overweight }\left(85^{\text {th }}-100^{\text {th }} \text { weight for length }\right. \\
\text { percentile) }\end{array}$ & $40(16.6 \%)$ \\
\hline \multicolumn{2}{|l|}{ Maternal education } \\
\hline Graduate/postgraduate & $170(70.2)$ \\
\hline Secondary & $60(24.9)$ \\
\hline Primary/none & $10(4.2)$ \\
\hline \multicolumn{2}{|l|}{ Maternal occupation } \\
\hline Senior public servants/professionals & I 18 (49) \\
\hline $\begin{array}{l}\text { Intermediate public servants/Senior } \\
\text { School teachers }\end{array}$ & $24(10)$ \\
\hline Junior school teachers, drivers, artisans & $14(5.8)$ \\
\hline Petty traders, laborers, messengers & $41(17)$ \\
\hline $\begin{array}{l}\text { Unemployed/housewife/students/ } \\
\text { subsistence farmers }\end{array}$ & $44(18.3)$ \\
\hline \multicolumn{2}{|l|}{ Religion } \\
\hline Christian & $209(86.7)$ \\
\hline Muslim & $28(11.6)$ \\
\hline \multicolumn{2}{|l|}{ Others } \\
\hline \multicolumn{2}{|l|}{ Tribe } \\
\hline Yoruba & $93(38.6)$ \\
\hline lgbo & $12 \mid(50.2)$ \\
\hline Hausa & $4(1.7)$ \\
\hline
\end{tabular}

Freq(\%)=Numbers (percentage)

of the children who were of healthy normal weight were accurately classified as normal by their mothers. More than half (54.3\%) of the children who were underweight were classified as normal by their mothers. However, all the children (100\%) who were overweight were misclassified as normal by their mothers. The overall prevalence of inaccuracy was highest (100\%) amongst the mothers of overweight children and was lowest amongst the mothers of the underweight children (19.7\%).

\footnotetext{
๑ 2018 Global Health and Education Projects, Inc. 
Table 2: Silhouette classification by mothers

\begin{tabular}{|c|c|c|c|}
\hline Silhouette classification & Correct classification & Correct (\%) & Incorrect (\%) \\
\hline Silhouette I & Underweight & 88.4 & 11.6 \\
\hline Silhouette 2 & Normal & 51.8 & 48.2 \\
\hline Silhouette 3 & Normal & 74.5 & 24.5 \\
\hline Silhouette 4 & Normal & 77.6 & 22.4 \\
\hline Silhouette 5 & Normal & 87.0 & 13.0 \\
\hline Silhouette 6 & Overweight & 70.0 & 30.0 \\
\hline Silhouette 7 & Overweight & 95.0 & 5.0 \\
\hline
\end{tabular}

$\%=$ Percentage

Table 3:Toddler nutritional status, and accuracy of maternal perception

\begin{tabular}{lcccc}
\hline Parameter & & \multicolumn{2}{c}{ Accuracy of maternal perception, N (\%) } \\
\cline { 5 - 6 } Nutritional status & & Accurate & Inaccurate perceived to be smaller & Inaccurate perceived child to be bigger. \\
\hline Total (Overall) & $60(41.1)$ & $51(34.9)$ & $35(24.0)$ \\
\hline Underweight & $12(26.1)$ & $9(19.6)$ & $25(54.3)$ \\
\hline Normal & $48(50.5)$ & $37(38.9)$ & $10(10.5)$ \\
\hline Overweight & $0(0)$ & 100 & 0
\end{tabular}

$\mathrm{N}(\%)=$ Frequency (Percentages)

\subsection{Determinants of maternal accuracy}

On univariate analysis, the maternal accuracy was positively significantly associated with the mother's educational status $(p=0.008)$, the tribe $(p=0.002)$, age of the child $(p=0.000)$ and the child's nutritional status $(p=0.000)$. Maternal accuracy was not associated with the maternal occupation $(p=0.598)$, religion $(p=0.663)$ and child's gender $(p=0.672)$. However, on multivariate analysis, (table 4$)$ only maternal education $(p=0.000)$, tribe/ethnicity, and child's nutritional status/toddler size were found to be associated with maternal accuracy to predict child's overweight status.

\section{DISCUSSION}

In this study, an assessment of nutritional status of toddlers between 12 and 36 months was determined and a validated 7-point silhouette scale was used to evaluate the body sizes of toddlers by a cohort of Nigerian mothers. The scale has been proven to be age, gender and racial neutral,' but it is yet to be extensively used in the population of children in Africa. Majority of the mothers in the present study could correctly order and identify the extremes of the silhouettes ( $I$ and 7) i.e. the underweight and the overweight silhouettes. This is consistent with the findings of other workers that have used the toddler scales. ${ }^{1,7}$ However, we found that a lower proportion of mothers could identify the normal toddler silhouettes (2-4) as normal weight children and about half of the mothers could not differentiate one of the normal silhouettes (Silhouette 2) from the underweight silhouette. Failure to identify one of the normal silhouettes may be related to the fact that there are many images representing the normal silhouette in the scale. Other plausible reasons may be the lack of training of the mothers to recognize the ideal body size in this group of children which may sometimes be difficult for the untrained eyes. ${ }^{10-13} \mathrm{~A}$ similar observation has been made by Hager et al.' and these workers have suggested that in order to obtain adequate accuracy from the use of the toddler silhouette scales there may be a need for the reduction of the numbers of the silhouettes which would require less visual discrimination among the images and highlight the different extremes even more clearly.' However, it was noted that fewer silhouettes choices may make it difficult to determine parental dissatisfaction which is interpreted by a difference of two or more images. ${ }^{1,12}$ Nevertheless, it is preferable 
Table 4: Multiple logistic regression of factors that determine maternal accuracy of child weight status

\begin{tabular}{lcccccc}
\hline Parameter & Regression coefficient & Standard error & Wald & P value & Odd's ratio ra & 99 95\% Cl \\
\hline Maternal education & -1.641 & 0.352 & 21.695 .219 & 0.000 & 0.194 & $0.097-0.387$ \\
\hline Maternal occupation & 0.238 & 0.347 & 0.470 & 0.493 & 1.269 & $0.643-2.504$ \\
\hline Religion & -0.489 & 0.521 & 0.880 & 0.348 & 0.613 & $0.221-1.704$ \\
\hline Tribe/ethnicity & -0.956 & 0.374 & 6.541 & 0.011 & 0.355 & $0.185-0.800$ \\
\hline Child's gender & 0.005 & 0.344 & 0.000 & 0.989 & 1.005 & $0.512-1.971$ \\
\hline $\begin{array}{l}\text { Child's nutritional } \\
\text { status/toddler size }\end{array}$ & -1.702 & 0.391 & 18.917 & 0.000 & 0.182 & $0.085-0.393$ \\
\hline
\end{tabular}

$\mathrm{Cl}$ - Confidence Interval, $\mathrm{P}$ value $<0.05$ is significant

that the mothers are able to identify abnormal nutrition states i.e. underweight and overweight which may prompt them to seek appropriate therapy and intervention.

Health professionals, on the other hand, have been observed to order these toddler silhouettes correctly from the thinnest to the overweight silhouettes and have better discrimination for the different silhouette compared to the parents.' This finding can be attributed to their training and exposure. Similarly, studies on silhouette scales on adolescents and adults have reported more accurate identification of silhouette sizes and body images compared to reports on toddler silhouette scales. ${ }^{14-17}$ In terms of maternal perception and accuracy in determination of their children's body size, the overall accuracy obtained in the present study was in $41.1 \%$ which is higher than that obtained by Hager et $\mathrm{al}^{12}(30.2 \%)$ in a group of African American mothers in the United States. However, the study involved a larger and more heterogeneous group than the mothers in our study.

In the present study, the highest prevalence of inaccuracy was found among mothers of overweight children who classified their children as normal. This is consistent with the findings from prior studies especially among mothers of preschool children who have been observed to be less accurate at determining the body sizes of their children compared to mothers of school aged children. ${ }^{5-7}$

Maternal overestimation of their children's body sizes has been previously documented in

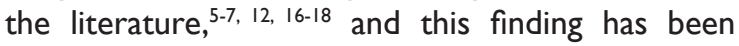
attributed to, and appears consistent with, the theory of idealization where parents fail to recognize discrepant body sizes and tend to idealize their children's body size as being normal. ${ }^{12}$ This is even more so for the mothers of the overweight children as high weight status is often seen as a sign of successful parenting. ${ }^{12,19}$ In a systematic review by Parry et al. ${ }^{20}$ it was observed that parents of overweight children often do not recognize that their children were overweight. More than two third (19) of the 23 studies reviewed in the article revealed that the parental perception of weight in the children was less than $50 \%$. This misperception is worrisome as failure to recognize undernutrition or overnutrition will result in inappropriate feeding and parental practices. In addition, the mothers would not see the need to seek for nutritional interventions.

It is important to note that overweight at a young age predisposes to overweight in adulthood and early intervention especially before the age of 5 years, can reduce this risk of adult obesity. ${ }^{20}$ Failure of parents to recognize childhood overweight may be a significant barrier to obesity prevention. Thus, it is important to educate the parents on the issue of overweight/obesity and its attendant complications because the parents play a significant role in the successful management and prevention of obesity. Similarly, failure to recognize under nutrition and its attendant complications has grievous consequences on the child's growth and development. ${ }^{20}$

In the present study, the factors that could predict the maternal accuracy in the determination of the toddler size were the maternal education, tribe/ ethnicity and the toddler size.This finding is consistent with the observation of other studies. ${ }^{1,12}$ Generally, it 
is known that maternal education plays a significant role in determining the nutritional status and survival of any child and still remains one of the key pillars of the child survival strategies. ${ }^{16,18}$ The role of ethnicity is variable $\mathrm{e}^{21-23}$ and some other authors have not found a significant relationship between ethnicity and accuracy. ${ }^{25}$ However, it has been observed that both ethnicity and education significantly associated with maternal perception and the prevalence of childhood obesity or otherwise. ${ }^{2,23-25}$ There are several other reports where the authors have observed that the maternal BMI may influence maternal accuracy in the determination of toddler body size. ${ }^{21-24}$ Although overweight mothers have been found to be less accurate in estimating the toddler body size compared to normal weight and underweight mothers, ${ }^{19,24}$ we did not examine the influence of maternal BMI.

\section{I. Limitations}

Since the study was cross sectional in nature, the influence of the child's growth trajectory on the maternal accuracy was difficult to determine. It would be desirable to conduct a community-wide survey with larger simple size and possibly explore other factors that may determine maternal accuracy.

\section{Conclusions and Global Health Implications}

This study has demonstrated that with the use of a toddler silhouette scale, mothers are able to identify extreme abnormal silhouettes and body sizes of toddlers thus the scale can be of considerable use by caregivers in assessing their children's nutritional status. However, there is a need for more studies on the use and probably the modification of the scale for use in the Nigerian context. The maternal accuracy obtained in this study is still far from desirable. Thus, there is a need for parents and caregivers to be educated and trained to accurately assess the body size of their children. This will potentially contribute in the prevention of under nutrition and obesity and ultimately promote healthy growth and development of children in Africa.

\section{Compliance with Ethical Standards}

Conflict of Interest: The authors declare no relevant conflict of interest. Ethics Approval: Ethical approval

\section{Key Messages}

- Awareness of toddler silhouette scales is low among mothers in Nigeria as in many of the developing countries.

- The use of the silhouette scale may be a simple and quick method to empower mothers in assessing their children's nutritional status.

- There is a need for training of mothers and other caregivers in the accurate assessment of body sizes of their children using the silhouette scale.

was obtained from the Health Research and Ethics Committee of the Lagos University Teaching Hospital. Informed written consent was obtained from the parents of the children and confidentiality of all the information obtained from the study participants was ensured.

\section{References}

I. Hager ER, McGill AE, Black MM. Development and validation of a toddler silhouette scale. Obesity. 2010; 18(2):397-40 I.

2. Caprio S, Daniels SR, Drewnowski A, Kaufman FR, Palinkas LA, Rosenbloom AL, Schwimmer JB. Influence of race, ethnicity, and culture on childhood obesity: implications for prevention and treatment: a consensus statement of Shaping America's Health and the Obesity Society. Diabetes Care. 2008; 3 I (I I):22I I-2I. doi: 10.2337/dc08-9024

3. Eke CB, Ubesie AC, Ibe BC. Challenges of childhood obesity in a developing economy: A review. Nigerian Journal of Paediatrics 2015; 42 (3): 169 - 179

4. Senbanjo IO, Adejuyigbe EA: Prevalence of overweight and obesity in Nigerian preschool children. Nutrition and Health 2007, 18:39I-399.

5. Eckstein KC, Mikhail LM, Ariza AJ, Thomson JS, Millard SC, Binns HJ; Pediatric Practice Research Group. Parents' perceptions of their child's weight and health. Pediatrics. 2006; 117 (3):68I-690.

6. Towns N, D'Auria J. Parental perceptions of their child's overweight: an integrative review of the literature. Journal of Pediatric Nursing. 2009; 24 (2): I I 5- I 30.

7. Carnell S, Edwards C, Croker H, Boniface D, Wardle J. Parental perceptions of overweight in 3-5 
y olds. International Journal of Obesity (Lond). 2005; 29(4):353-355.

8. Marfell-Jones M. International Standards for Anthropometric Assessment. International Society for the Advancement of Kinanthropometry. South Africa: Potchefstroom; 2006.

9. Ogden CL, Kuczmarski RJ, Flegal KM, Mei Z, Guo S, Wei R, Grummer-Strawn LM, Curtin LR, Roche AL, Johnson CL. Centres for Disease Control and Prevention 2000 Growth Charts for the United States: Improvements to the National Centre for Health statistics Version. Pediatrics. 2000; 109:4560.

10. Wald ER, Ewing LJ, Cluss P, et al. Parental perception of children's weight in a paediatric primary care setting. Child Care Health Development. 2007; 33(6):738-743.

II. Baughcum AE, Chamberlin LA, Deeks CM, Powers SW, Whitaker RC. Maternal perceptions of overweight preschool children. Pediatrics. 2000; I06(6): 1 380-1386.

12. Hager ER, Candelaria M, Latta LW, Hurley KM, Wang Y, Caulfield LE, Black MM. Maternal Perceptions of Toddler Body Size Accuracy and Satisfaction Differ by Toddler Weight Status. Archives of Pediatrics and Adolescent Medicine. 20I2;166(5):417-422.

13. Pulvers KM, Lee RE, Kaur $\mathrm{H}$ et al. Development of a culturally relevant body image instrument among urban African Americans. Obesity Research 2004; 12: |64|-|65|.

14. Tehard B, van Liere MJ, Com Nougué C, ClavelChapelon F. Anthropometric measurements and body silhouette of women: validity and perception. Journal of American Dietetics Association 2002; I02:1779-1784.

15. Mitola AL, Papas MA, Le K, Fusillo L, Black MM. Agreement with satisfaction in adolescent body size between female caregivers and teens from a low income African-American community. Journal of
Pediatrics Psychology 2007; 32:42-5I.

16. Huang JS, Becerra K, Oda T et al. Parental ability to discriminate the weight status of children: results of a survey. Pediatrics 2007; I20:e I I2-el I 9.

17. Oude Luttikhuis HG, Stolk RP, Sauer PJ. How do parents of 4- to 5-year-old children perceive the weight of their children? Acta Paediatrics. 2010, 99 (2): 263-267.

18. Laraway KA, Birch LL, Shaffer ML, Paul IM. Parent perception of healthy infant and toddler growth. Clinical Pediatrics (Phila). 20I0; 49(4):343-349.

19. Stunkard AJ, Sørensen T, Schulsinger F. Use of the Danish Adoption Register for the study of obesity and thinness. Res Publ Assoc Res Nerv Ment Dis 1983; 60: II5-120.

20. Parry LL, Netuveli G, Parry J, Saxena S. A systematic review of parental perception of overweight status in children. Journal of Ambulatory Care \& Management 2008; 31: 253-68.

21. Warschburger P, Kröller K. Childhood overweight and obesity: maternal perceptions of the time for engaging in child weight management. BMC Public Health 20 I2; I2:295. doi: I0.I I86/ |47| I-2458-I2-295.

22. Mamun AE, McDermott BM, O'Callaghan MJ, Najman JM, Williams GM. Predictors of maternal misclassification of their offspring's weight status: a longitudinal study. International Journal of Obesity. 2008; 32: 48-54. 10.1038/sj.ijo.0803757.

23. Chaparro MP, Langellier BA, Kim LP, Whaley SE. Predictors of Accurate Maternal Perception of Their Preschool Child's Weight Status Among Hispanic WIC Participants. Obesity 20II; 19: 2026-2030. doi:10.1038/oby.2011.105.

24. Killion L, Hughes SO, Wendt JC, Pease D, Nicklas TA. Minority mothers' perceptions of children's body size. International Journal of Pediatric Obesity 2006; I:96-102.

25. Etelson D, Brand DA, Patrick PA, Shirali A. Childhood Obesity: Do parents recognize this health risk? Obes Res. 2003; I I: I362-1368. 10.1038/oby.2003.184.. 